\title{
Las redes y los movimientos sociales ¿una acción colectiva o marketing viral?
}

\section{Social networks and social movements: Collective action or viral marketing?}

\author{
Jesús Esteban Cárcar Benito \\ Profesor Asociado de Ciencia Política y de la Administración \\ Doctor en Derecho: Licenciado en Ciencias Políticas y Sociología \\ (Umiversidad de Murcia)
}

Fecha de recepción: 10 de octubre de 2014

Fecha de revisión: 15 de enero de 2015

Para citar este artículo: Cárcar Benito, J.E. (2015): Las redes y los movimientos sociales ¿una acción colectiva o marketing viral?, Icono 14, volumen (13), pp. 125-150. doi: 10.7195/ri14.v13i1.744 


\section{Resumen}

Desde los últimos años, se ha extendido el debate sobre el papel de los movimientos sociales y su relación con las tecnologías de la información y la comunicación (TIC). Los "nuevos movimientos", cuentan con más de veinte años de existencia, son ya clásicos en la actualidad, se ven como tradicionales, e incluso, con un marcado carácter institucional. Para entender la evolución y características de los movimientos sociales, y su papel dentro de las nuevas tecnologías, analizaré primero la estructura del marketing para los movimientos sociales; en segundo lugar, su implementación; finalmente, algunas consideraciones sobre sus campañas.

\section{Palabras clave}

Comunicación - Mensaje - Movimientos sociales - Marketing viral

\section{Abstract}

Since the last few years there has been widespread debate about the role of social movements, and its relation to ICTs. The " new movements " that have over twenty years of existence are classics today, are seen as traditional, and even with a strong institutional and also face the new challenges of Web 2.0 communication to understand the evolution and characteristics of social movements, and their role within the new technologies Firstly I would like to discuss the structure of marketing for social movements; secondly, their implementation; finally, some considerations for their campaigns.

\section{Key Words}

Communication - Message - Social movements - Viral marketing 


\section{Introducción: objetivos y metodología}

La mayoría de las aproximaciones al estudio de la acción colectiva (movimientos, asociaciones, ONGs etc.) se han caracterizado por concebir la existencia de intereses exógenos que la determinaban, limitando por ello la importancia y sustantividad que la propia acción tenía. Cuando analizamos el concepto de "movimiento social" nos referimos a un amplía gama de intentos colectivos de efectuar cambios en determinadas instituciones sociales o crear un orden totalmente nuevo. Subrayamos como rasgo definitorio su voluntad de cambio social. A lo largo del presente estudio, vamos a tratar de mostrar cómo han evolucionado estas aproximaciones para acercarse a planteamientos en los que la acción, estructura organizativa y comunicación, a través de las TIC, se funden en una dotación completa de significado.

Es necesario observar que tienen una forma de acción que les lleva a evitar, conscientemente, los medios convencionales de participación y los ámbitos institucionales de expresión. Una delimitación de la comunicación política nos indica que estamos ante un objeto del área de conocimiento pluridisciplinario, que puede ser definida como el proceso de gestión de la visibilidad del ejercicio de poder de quienes lo tienen, lo aspiran, lo respaldan o lo contrarían. En ese proceso se incluyen las estrategias de construcción, intercambio y recepción de discursos (Sibaja Quesada, p.115).Empero, Wolton (1998, p.111-112) destaca el acento político de la comunicación, enfocándolo en la toma de decisiones, en la movilización para la acción, más que la comunicación por sí misma para vehiculizar un cierto tipo de información.

Pese a lo anterior, su naturaleza extrainstitucional lleva a asumir la protesta como forma de acción y de expresión organizada. Para ser operativo, aplica al proceso de movilización el marketing como un conjunto de técnicas de planificación y comunicación.

Dependiendo del público al que se pretende llegar, una de las técnicas emergentes en estos contactos es el denominado marketing viral, consistente en la difusión rápida y masiva de un mensaje en la red, cuya eficacia es realizar una oferta

DOI: ri14.v13i1.744 | ISSN: 1697-8293 | Año 2015 Volumen 13 Nº 1 | ICONO14 
atractiva en la página Web de una organización, que se da a conocer a través, casi siempre, de un correo electrónico. Por tanto, el marketing viral intenta explotar las redes sociales para producir incrementos exponenciales en conocimiento del mensaje (marca o mensaje) de forma análoga a la expansión de un virus informático (Montañés del Río, M. et al, 2014). Se basa en el boca a boca mediante medios electrónicos, es decir, de las tecnologías de la información en sus nuevos formatos para alcanzar al mayor número de personas. En efecto, debemos analizar la importancia de las redes y la gestión de las mismas para los movimientos sociales, entendiéndolas como una herramienta de comunicación y difusión. Surge el ciberactivismo como movilización desde el conjunto de las TIC que posibilitan mayor difusión de información y una gran audiencia. La pregunta es si el ciberactivismo es una estrategia próxima al marketing viral, dado que supone la inclusión de un nuevo asunto en el orden del día de una "estructura de oportunidad", variable interna de un movimiento, que propaga y difunde un determinado mensaje a través del "boca a boca" multiplicado por los medios de comunicación y publicación electrónica personal (Ugarte D., 2007).

\subsection{Metodología}

1. Búsqueda de información (en centros de documentación, bases de datos, y a través de Internet).

2. Análisis crítico de la naturaleza de los datos secundarios y la metodología empleada en su elaboración.

3. Extracción de los datos relevantes para los objetivos de investigación propuestos.

4. Reelaboración y análisis de la información proporcionada por las fuentes secundarias.

5. Síntesis y presentación de los principales resultados de la investigación. 


\section{Marco y estrategias de marketing social en las redes sociales}

El auge de las redes sociales deviene del cambio de panorama tecnológico donde se aumenta el ancho de línea y la llegada de las tarifas planas haciendo que sea accesible a todos los ciudadanos, de todas las clases sociales. Esto es muy atractivo desde el punto de vista del marketing directo, ya que permite que el usuario interaccione directamente con los elementos Web en el caso de las páginas $1.0 \mathrm{y}$ que incluso los anuncios sean seleccionados, dependiendo de las preferencias del usuario, en el caso de las redes sociales.

Desde el punto de vista del marketing estratégico, las redes sociales son un acceso a un público objetivo ya segmentado, pues a la hora de hacer el registro son cumplimentados campos como la ideología del usuario, domicilio, su tendencia política, sexo y edad. Esto produce una fácil evaluación del público que está expuesto al mensaje y su respuesta. Además, operan controlando eficazmente los mensajes emitidos y tienen la posibilidad de rectificación en caso de fallo (Barquero Cabrero J., 2005). A pesar de las facilidades que presentan las redes sociales para la segmentación de la campaña de un movimiento, da la sensación de ser un medio no suficientemente explotado.

Las redes sociales, los blogs o las Webs de los movimientos deben estar en continuo intercambio con las personas que se encuentren enlazadas. Los perfiles y la población diana tendrían que estar continuamente actualizados, y haber un diálogo entre los representantes de los movimientos o miembros de comunicación y sus contactos, y este intercambio ser público.

En España, al igual que ha ocurrido en otros países de nuestro entorno, las formaciones y movimientos han apostado por la inserción de las TIC en el desarrollo de la acción colectiva y movilización, como herramientas destinadas a la comunicación y transmisión de contenidos para completar los procesos de interrelación tradicionales con los ciudadanos. Las oportunidades que brinda Internet a los movimientos sociales precisan de un desarrollo amplio del marketing y su aplicabilidad en las nuevas herramientas de comunicación (Borge Bravo, R., 2005).

DOI: ri14.v13i1.744| ISSN: 1697-8293 | Año 2015 Volumen 13 N 1 | ICONO14 
España es el país europeo en el que los usuarios de telefonía móvil utilizan más los servicios de mensajería instantánea independientes como WhatsApp, servicios de Internet sin mediar control por parte de los operadores de red, over the top; el $51,5 \%$ de los usuarios de móvil los usan diariamente y el $83 \%$ de los usuarios de smartphone lo emplean al menos una vez por semana, muy por encima otros países europeos, según el Informe sobre servicios 0TT- en España publicado por la Comisión Nacional de los Mercados y la Competencia - CNMC -2014. España presenta, en general, unos valores elevados en la utilización de servicios de comunicación y acceso a la información, especialmente en lo que se refiere a la participación en redes sociales (interacción social), que llevan a nuestro país a situarse por encima de la media europea en esta materia. Según datos del Instituto Nacional de Estadística (INE), el 64\% de los internautas participaron en redes sociales en 2013, lo que supone un incremento de casi un $5 \%$ con respecto a 2012. Del tiempo dedicado a la comunicación social, el 45\% es para chatear. En este escenario, según el IV Estudio de Redes sociales online de Interactive Advertising Bureau (IAB Research Spain) de enero de 2013, la penetración en redes sociales está alcanzando su madurez. Casi 8 de cada 10 internautas de entre 18 y 55 años utilizan redes sociales y, según el Estudio de Medios de Comunicación online 3, de IAB, 8 de cada 10 internautas pasan más de una hora diaria en las redes sociales y, de ellos, el $9 \%$ pasa más de cuatro horas en las mismas.

Si se atiende a los usos del teléfono móvil, sus usuarios pasan la mitad del tiempo que utilizan sus dispositivos con actividades relacionadas con la comunicación social. Como consecuencia de ello, las aplicaciones más descargadas durante 2013 fueron WhatsApp, Facebook y Twitter. En este sentido, se puede afirmar que la participación social se ha convertido en una actividad clave con relación a los usos de Internet en España. Asimismo, los internautas españoles continúan por encima de la media comunitaria en la lectura de periódicos, noticias y revistas online, si bien este dato se ha visto disminuido con respecto a 2012 (Fundación Orange Informe eEspaña 2014).

El paso del tiempo, por tanto, ha generado nuevas reglas relacionadas con la competencia en los campos de la acción colectiva, provocando cambios sustancia- 
les en algunos aspectos básicos de las mismas que influirán en la forma de organización, dirección y desarrollo de los movimientos sociales (Canel, M., 1999).

\subsection{Los procesos}

La proliferación de los recursos en Internet crece a un ritmo frenético y van adquiriendo una sofisticación cada vez mayor. Esto provoca la necesidad que tienen los estrategas de movimientos sociales de experimentar primero e implementar después nuevas formas de comunicación y nuevos procesos de participación. Al igual que ocurrió con las grandes transformaciones que tuvieron lugar en la segunda mitad del siglo pasado, las innovaciones tecnológicas que se han venido produciendo en los últimos años afectan también a la actividad desarrollada alrededor de los nuevos mensajes. Coexiste una personalización de lo movimientos, que requiere la adaptación de la ciudadanía a esta nueva realidad, con el fin de lograr una estructura mental acorde con ella.

La asociación entre la difusión del mensaje de un movimiento social y TIC permite llegar a un mejor conocimiento de las demandas sociales amplía las posibilidades de comunicación con la ciudadanía, haciendo que la información circule en un sentido bidireccional. Es evidente, que este nuevo contexto hace que la comunicación mediática haya adquirido un protagonismo relevante, lo que obliga a las formaciones políticas y sociales a adaptarse a la nueva realidad de los medios. Con las nuevas tecnologías, la información se propaga con gran rapidez, casi de forma inmediata, lo que obliga al movimiento y a su organización a asimilar este cambio y tener preparados planes de choque para situaciones de crisis. Con esta nueva realidad, los Webs sites de las formaciones, los blogs de los líderes, las redes sociales, el marketing viral o el envío de mensajes de contenido político, a través de Internet, se unen a las herramientas utilizadas en las estrategias tradicionales.

\section{La cibersociedad y sus ventajas}

El hallazgo de nuevas fuentes de difusión y de herramientas y canales de comunicación resulta esencial para las formaciones sociales. Los soportes de Internet

DOI: ri14.v13i1.744 | ISSN: 1697-8293 | Año 2015 Volumen 13 Nº 1 | ICONO14 
destacan entre ellos. Buscamos un hilo directo con el receptor, evitando las mediaciones innecesarias o interesadas. Una comunicación personalizada, próxima, espontánea, involucrada, en definitiva, una nueva vía de consecuencias imprevisibles.

Entre las ventajas que ofrece internet a los movimientos sociales en la cibersociedad estarían: ser creadores de vida social e incrementar los canales de información y su volumen, ofreciendo más datos y aumentando las posibilidades de reflexión y decisión sobre una gran diversidad de temas. Es decir, suprimir las barreras geográficas para la participación (Borge Bravo,R. ,2005), y así incrementar la cantidad y la calidad de la información de los ciudadanos con independencia de su ubicación. De igual modo, permite mejores soluciones y más representativas; hace proliferar los foros de debate público; recoge estudios de opinión, de forma inmediata; asume que el éxito del movimiento está determinado por factores estratégicos.

\section{El escenario cercano y sus herramientas}

Con la intención de captar el espíritu de su tiempo y mantenerse en armonía con las tendencias sociales más actuales, los movimientos sociales se lanzan a la red conocedores de su importancia. La actividad propagandística está cambiando, pero también se está homogeneizando en todo el mundo, ya que los líderes sociales miran de forma constante a sus 2.0. El sitio se sirve de las redes sociales para "conectar" a los simpatizantes e interesados.

En campañas de protesta social han destacado: youtube, twitter y facebook. Los videos producidos en los movimientos sociales (youtube) han sido videos pensados para que los internautas los compartan de forma viral en la red, adquieran notoriedad y acaben generando noticia en el resto de medios. Facebook ha sido la red social en la que los movimientos acumulaban ya alguna experiencia, ya sea mediante perfiles y páginas personales, o a través de grupos de apoyo personal o institucional. No obstante, se ha dado un pequeño paso adelante avanzando en su uso con el fin de crear conversación, enriquecer los mensajes y no limitarse utilizando como almacén de archivos de fotos, vídeos y declaracio-

ICONO14 | Año 2015 Volumen $13 N^{\circ} 1$ | ISSN: 1697-8293 | DOI: ri14.v13i1.744 
nes de los líderes de los movimientos y participantes en la protesta. Twitter ha tenido también un papel destacado.

La mayoría de los estudios coinciden en destacar, que si bien se ha avanzado en la expansión de las aplicaciones basadas en la nueva tecnología Web 2.0, no hay una actitud decidida por parte de los movimientos para aprovechar al máximo todos los recursos de la red. Parece ser que lo que está sucediendo con Internet guarda gran semejanza con lo ocurrido en su día con la televisión, cuyo potencial no se explotó plenamente hasta pasados unos años desde su aparición (Hirschman, 1986).

\section{Los movimientos sociales en red y su nueva es- tructura}

Para Castells, (1997, p. 385-386) los movimientos sociales puede ser decisivos como salida a la situación planteada en esta sociedad de la información ya que, frente a la presión, aparentemente irresistible, de los grupos que controlan la globalización económica y política, los movimientos se atreven a situarse fuera de la cultura establecida y a ofrecer "un sistema de valores completamente diferente", construyendo nuevos códigos y nuevas identidades.

Como consecuencia de las transformaciones que proporciona la era digital, las formaciones sociales necesitan caminar a la misma velocidad y disponer de las herramientas conceptuales, técnicas y tecnológicas adecuadas que les permitan optimizar, y hacer más eficiente el desarrollo de su trabajo, incrementando el alcance de su mensaje. Para ello, los movimientos sociales se deben mostrar dispuestos a implementar mecanismos electrónicos en su estructuración, organización y funcionamiento.

A los movimientos sociales les interesa tener un cierto control sobre lo publicado por los medios de comunicación para que su mensaje llegue como ellos desean, sin la intervención de intermediarios. Internet concede la posibilidad de realizar una comunicación inmediata entre los responsables del movimiento y los ciudadanos, ya sean militantes, simpatizantes o simplemente personas

DOI: ri14.v13i1.744 | ISSN: 1697-8293 | Año 2015 Volumen 13 Nº 1 | ICONO14 
interesadas en seguir las reflexiones, deliberaciones y debates que se llevan a cabo en el seno de la organización.

El uso de las TIC supondría una mejora en el funcionamiento interno de la organización, facilitando el trabajo colaborativo entre sus miembros y mejorando la comunicación corporativa entre sus diferentes sedes territoriales. Una infraestructura organizativa armónica permitirá satisfacer estas necesidades comunicativas integrando en una plataforma única la comunicación interna y externa de la formación. La configuración de una estructura global de comunicación fomentará la horizontalidad y la participación directa de las bases y de los miembros de las distintas organizaciones locales, evitando una sensación de aislamiento y fomentando su cohesión como parte del grupo, siendo la comunicación bidireccional y, prácticamente simultánea, a un bajo coste.

Sostienen Sey y Castells (2006, p. 456) que sería un error utilizar internet como una reproducción de la movilización tradicional, de arriba a abajo, controlada en todo momento por la maquinaria de los movimientos. Internet se convierte en una herramienta potente cuando se dispone de un programa abierto, lo que implica ausencia de control central y la configuración de la red alrededor de temas generales, cuya especificidad derive de un proceso interactivo, dinámico y recurrente dentro de la propia red. Los movimientos se nos muestran así como estructuras organizadas que tienen éxito en función de estos recursos, y no como el resultado de la impotencia de la sociedad.

\section{Movilización en internet}

Como ya se ha venido señalando, Internet se está convirtiendo en un medio esencial que está condicionando las estrategias de comunicación y organización en todos los ámbitos de actividad para los movimientos sociales. Su uso y desarrollo irá encaminado a construir una identidad digital que permita convertirla en una herramienta privilegiada para actuar, informar, reclutar, organizar, dominar y contradominar (Castells 2001, p. 159).

ICONO14 | Año 2015 Volumen $13 N^{\circ} 1$ | ISSN: 1697-8293 | DOI: ri14.v13i1.744 
No resulta fácil determinar en qué medida la movilización y lo que sucede durante el desarrollo de la protesta, como tampoco lo es conocer en qué medida Internet incide en la manera de pensar y actuar de los ciudadanos. No obstante, resulta evidente cómo aporta cada vez más al desarrollo de los movimientos sociales. El papel protagonista que juega internet en el transcurso de los últimos años, donde gran parte de la estrategia de comunicación se apoyó en las herramientas de la Web 2.0, ha sido determinante para reconocer la importancia de la presencia online y la necesidad de desarrollar nuevas estrategias de acción en nuevos escenarios. Su naturaleza extrainstitucional les lleva a asumir la protesta como forma de acción y expresión política organizada, haciendo de lo medios e instrumentos sus aliados naturales, no sólo como canal de expresión sino, también, como medio de movilización.

En definitiva, se está produciendo un cambio de paradigma en la forma de movilizar y, por tanto, en la manera de afrontar las estrategias de actuación, lo que conducirá a redefinir el panorama de la acción social. Ello implica la necesidad de adoptar modelos de organización que permitan sacar el máximo provecho a ese potencial y la adecuación y modernización tanto de las estructuras de las organizaciones, si las tienen, como de sus modelos de operación. Se asiste a un proceso de transformación de la vida social mejorando la transparencia en la actuación de los actores políticos, propiciando la participación activa de los ciudadanos.

\section{Características de los formatos 2.0.}

El desarrollo tecnológico puede aportar nuevos formatos para mejorar los efectos positivos de la comunicación política y la participación en acciones de protesta que puede traducirse en presión sobre las instituciones a favor del cambio propuesto por el movimiento (Ugarte (de), D., 2007). El formato permite llegar más directamente al ciudadano, a los usuarios, el mensaje político social original sin la intervención de intermediarios. Esto facilita a las formaciones una vía de contacto directo, sin necesidad de tener que atravesar los filtros mediáticos y consiguiendo una interacción y un feedback con la ciudadanía, lo que permite un intercambio de información de los mensajes de un movimiento (León, 0.; Burch, s. y Tamayo, E., 2001). Los ejes son las siguientes:

DOI: ri14.v13i1.744 | ISSN: 1697-8293 | Año 2015 Volumen 13 N 1 | ICONO14 
1. El nuevo escenario concede a los movimientos sociales una imagen de novedad, modernidad, versatilidad, accesibilidad, dinamismo e innovación acorde a la progresión, directo, abierto, horizontal y sin filtros que permite salvar las limitaciones de tiempo y espacio.

2. El usuario puede acceder a la información cuando quiera, sin limitaciones de tiempo ni de distancia.

3. Supone una reducción considerable de los costes para llegar al ciudadano.

4. La plataforma on line ofrece múltiples herramientas que simplifican el diseño y reducen los costes. Internet resulta más económico e ilimitado para darse a conocer que cualquier otro medio convencional

5. Además, permite medir la efectividad de la campaña, lo que facilita que se puedan dirigir los esfuerzos de forma más correcta. Si la estrategia se diseña de una forma adecuada, Internet se configura como un elemento crucial para la segmentación del mensaje electoral que permita su orientación hacia objetivos específicos.

6. Internet concede una mayor capacidad de reacción. Las estrategias de modificación y actualización de contenido resultan mucho más flexibles que en cualquier otro soporte comunicativo.

7. Incrementa las posibilidades de actuación e intervención de los ciudadanos, permitiéndoles desarrollar un papel más participativo e interactivo. Los electores dejan de ser receptores pasivos para manejar una gran diversidad de información lo que les permite influir e incluso construir el mensaje.

8. Además, es una vía ágil para la organización del grupo que requiere una vía adecuada, no sólo para reclutar activistas, simpatizantes y voluntarios desde la Web, sino también para su organización y movilización. En este sentido, se pretende buscar una mayor implicación de aquéllos, dando a conocer sus propuestas y canalizando las más interesantes hacia las áreas que correspondan. 
El nuevo formato se concentra en la acción colectiva no como un hecho, y sí como un proceso, que no excluye las relaciones sociales en un sistema de oportunidades y obligaciones (Sibaja Quesada, G., 2013).

\section{Planificación y desarrollo de estrategias comu- nicativas en la red}

Con el fin de elaborar un plan integral que permita despertar el interés ciudadano, persuadirlo y lograr una respuesta intensa de éste hacia la acción colectiva y la protesta, el diseño de la estrategia en cuestión dependerá de una planificación particularizada. Siguiendo las pautas dadas por Calvo y Reinares (2001, p.116118), la planificación de una estrategia publicitaria online exige un proceso. Así, los objetivos son pretendidos de acuerdo a las posibilidades existentes, así como a la diana (target) a la que se dirigen los mensajes, que deben centrarse en aquellos segmentos del sector ciudadano más familiarizados con el uso de las TIC. En esta etapa, habrá que dar respuesta a dos preguntas fundamentales: ¿qué mostramos cómo relevante en la comunicación? y ¿a quién se quiere comunicar?

En referencia al diseño del contenido y la forma de los mensajes, hay que seleccionar un eje de comunicación y transformarlo, dándole forma para que se traduzca en un mensaje claro, preciso, ordenado, directo y eficaz. Se busca respuesta a la pregunta cómo se dice lo que se quiere propagar. La elección de los soportes debe ser la estrategia de medios, a través de los cuales, se pretende difundir el mensaje. Serán utilizadas aquellas herramientas que se consideran más adecuadas para los fines pretendidos. La pregunta será: ¿A través de qué soportes se busca difundir el mensaje en la red? La etapa de implementación, seguimiento y verificación del cumplimiento de la estrategia diseñada supone una posible respuesta. Su desarrollo pretende alcanzar sus objetivos de la forma más óptima posible, para ello se deben realizar labores de control que permitan asegurar que se están utilizando los mensajes que más se adaptan al ciudadano objetivo y a la estrategia inicial planteada. Se busca medir la ejecución en relación a unos patrones de actuación para valorar si se han alcanzado o no los resultados previstos. La pregunta básica que se plantea es sobre qué objetivos o qué efectos se han conseguido.

DOI: ri14.v13i1.744 | ISSN: 1697-8293 | Año 2015 Volumen 13 Nº 1 | ICONO14 
Habrá que identificar, por tanto, aquellas estrategias más adecuadas que deben desarrollarse en Internet para liderar un proyecto de movilización de acción colectiva con éxito. En definitiva, se busca la puesta en marcha de propuestas óptimas de estrategia movilizadora con el fin de lograr el máximo grado de perfeccionamiento en el desarrollo de la acción, procurando extraer el máximo rendimiento a las nuevas tendencias de la comunicación política. El desarrollo de instrumentos eficaces que permitan obtener un uso adecuado de las nuevas herramientas comunicativas se convierte en un factor determinante para lograr el éxito.

\section{La identificación}

Podemos considerar la identidad colectiva como una forma de compromiso hacia la campaña. El aceptar la ideología, los marcos de acción, los recursos, y sentirse identificado e integrado en el grupo hace que el movimiento sea sólido y la movilización sea por consenso. El marco de acción se refiere a delimitar las demandas generalizándolas para abarcar a más gente y ampliar así en número. Pero además, definen las figuras "nosotros" y "ellos", se crean unas fronteras culturales y políticas (Tarrow, S., 1997). A través de la identidad, es posible la desaparición de la incertidumbre y la estabilidad de los valores que sirven de base para la construcción de preferencias (Funes, M.J., 2011). En consecuencia, los análisis de la identidad tienden a caer en un informe socio-psicológico de la interacción, a expensas de un verdadero análisis sociológico de conflicto. Internet asigna un nuevo modelo de acción colectiva en el que la identidad no se construye a través del reconocimiento, sino a través de un modelo cultural autorreflexivo.

La personalización es entendida como la focalización de la atención en los atributos de carácter del movimiento, quien llega a convertirse en una marca dentro del "mercado" simbólico (Lambin, J., 2003). La preocupación por la imagen del movimiento se corresponde con la predominante desideologización de la política. Esto conduce a un modelo de mensaje donde el protagonista pueden ser los líderes de un movimiento. Individuos que, a pesar de ser propuestos y sustentados por las organizaciones, tienden a aparecer menos como representantes de formaciones, $\mathrm{y}$ más como individuos que ofrecen su experiencia. 
La red impone nuevas lógicas a la práctica y se convierte en una herramienta, a través de la cual el líder de un movimiento puede construir su marca personal. La necesidad de crear una buena reputación digital online que permita la generación de percepciones positivas a favor del movimiento se convierte, más que en una oportunidad, en una necesidad para generar confianza.

Los movimientos quieren estar presente en ese nuevo escenario de conversación y para ello debe perfilar un yo digital con el fin de compartir espacios con su audiencia. Resulta, por tanto, inhabitual que un movimiento social no tenga una web con un apartado especial dedicado a la figura del líder o representante e incluso, con un protagonismo más amplio que otros espacios, como el dedicado a los principios y programas de una formación.

El conocimiento y la aplicación del concepto 2.0 implican un mensaje comprometido con el entorno digital, que busque construir una estrategia 2.0 con el objetivo de ganar adhesión. El marco de personificación sería la interactuación. Esta huella se estructura en torno a unos principios y unos valores que el líder social y el público podrán identificar con una serie de beneficios.

Estamos ante una nueva manera de afianzar su propia identidad digital, y conseguir que esta identidad digital sea su propia marca en la red. En todo caso, si bien el líder del movimiento 2.0, no hará ganar un proceso de identificación, si ayudará de forma determinante, formando parte de la arquitectura de una estrategia global de campaña debidamente articulada.

La reputación online no es algo que se construya de la noche a la mañana, sino que implica un proceso complejo de creación que, por el contrario, es muy fácil dañar y destruir en muy poco tiempo si no se tiene bien ordenada y definida. Por tanto, las iniciativas del movimiento en la red deben adaptarse a los principios y las reglas de este escenario. El paradigma es la construcción de una identidad personal del movimiento, a través de la propia acción colectiva y, por tanto, poner en relación ambas. 


\section{La implementación de las redes sociales}

A partir de una revisión de las grandes aportaciones de las TIC al mundo social, afirmamos que Internes es una herramienta de participación. Hay una fuerte transformación desde las acciones reactivas de los pequeños grupos de solidaridad hasta las actuales acciones proactivas de las grandes y compleja organizaciones (Cammaerts, B. \& Van Audnhove, L. V., 2003).

Resulta claro como estamos asistiendo al fortalecimiento de Internet y para ello el diseño, la organización, el contenido, y el contacto con el ciudadano se convierten en elementos fundamentales para seducir y persuadir a los destinatarios (Lasen, A. y Martinez, I., 2008). Por medio de la acción colectiva, se atraen nuevos apoyos, se refuerza la solidaridad o se restablecen las posiciones de amistad o enemistad. No es, pues, extraño que acción y organización dejen de tener carácter instrumental y pase a convertirse en fines.

Las formaciones sociales, conscientes de esta realidad, han incrementado su presencia en la red hasta el punto de que hoy es difícil encontrar una organización sin presencia en la misma durante el desarrollo de un proceso movilizador o de protesta. No obstante, la mera tenencia de una Web no garantiza su éxito. La permanente renovación de este entorno obliga a los nuevos movimientos y al ciberactivismo a adaptar sus contenidos y estrategias a las tecnologías y preferencias (Benett, W., 2003):

La presencia online puesta en marcha por los movimientos sociales debe estar en constante desarrollo. Ya no se limita a una presencia estática, como ocurría en convocatorias de movilizaciones anteriores, sino que, como regla general, ha ido progresando obteniendo una presencia más interactiva y llevando a cabo un mayor esfuerzo movilizador (Marí Sáez, V., 2006). Las actuaciones que se deben seguir para una correcta gestión de redes sociales, siempre tendrán que fijar los objetivos que se pretenden conseguir a través de la red, ya sea adherir a personas al movimiento, estudiar y generar corrientes de opinión o, puede ser que se pretenda, una recaudación de fondos. Por otra parte, dependiendo del fin que se persiga, deberán emplear unos métodos u otros. 
Así, los banners son anuncios estáticos o en movimiento que pueden variar al situar el cursor sobre ellos. Son elementos que pertenecen a páginas y suelen ser pequeños fragmentos de información que al clickear sobre ellos redirigen a una página. Normalmente suele ser la site del movimiento. Estos banners suelen alojarse en sitios afines al público que se pretende buscar. Las webs de los periódicos son útiles debido a que ya se tiene diferenciada y segmentada a la población. El problema que tienen los banners es la baja interacción que puede tener con ellos el usuario y la poca información que pueden aportar.

En las Webs de los movimientos sociales, se encuentran toda la información relevante. Se llega a través de ella por buscadores, en el caso de que exista una previa intención de información o por el interés generado por los banners. Son eficaces desde el punto de vista que ofrecen información actualizada sobre los contenidos y los cambios en la protesta, y que, además, mediante widgets pueden ofrecer extractos e interacción con otras redes sociales como canales de Youtube, o el microbloging de Twitter.

El correo electrónico personalizado (mailing), una vez que el usuario está en la base de datos, puede enviar correos personalizados para crear fidelización e interacción. En el caso de que la persona, aún no haya sido fidelizada, la intrusión puede ser mayor y ser tomado como correo basura (spam) lo cual daría una mala imagen para el movimiento.

Los mensajes a través del móvil siguen atendiendo a las tres cuartas de la población. La creciente demanda de teléfonos adaptados para Internet (smartphones) hace que este medio sea muy atractivo a la hora de lanzar campañas personalizadas. España es el país europeo, como hemos indicado, en el que los usuarios de telefonía móvil usan más los servicios de mensajería instantánea independientes como WhatsApp.

Las redes sociales son el canal idóneo si se pretende una interacción con el usuario y futuro consumidor del producto, en este caso, la acción colectiva. Son un canalizador de mensajes y esfuerzos por parte de la comunidad simpatizante, dándose un diálogo entre ellos y el agente encargado de la comunicación. La presencia y estrategia en las redes sociales favorecen significativamente el contacto directo de los movimientos con los ciudadanos.

DOI: ri14.v13i1.744| ISSN: 1697-8293 | Año 2015 Volumen 13 Nº 1 | ICONO14 
Penetración en el uso de las redes sociales

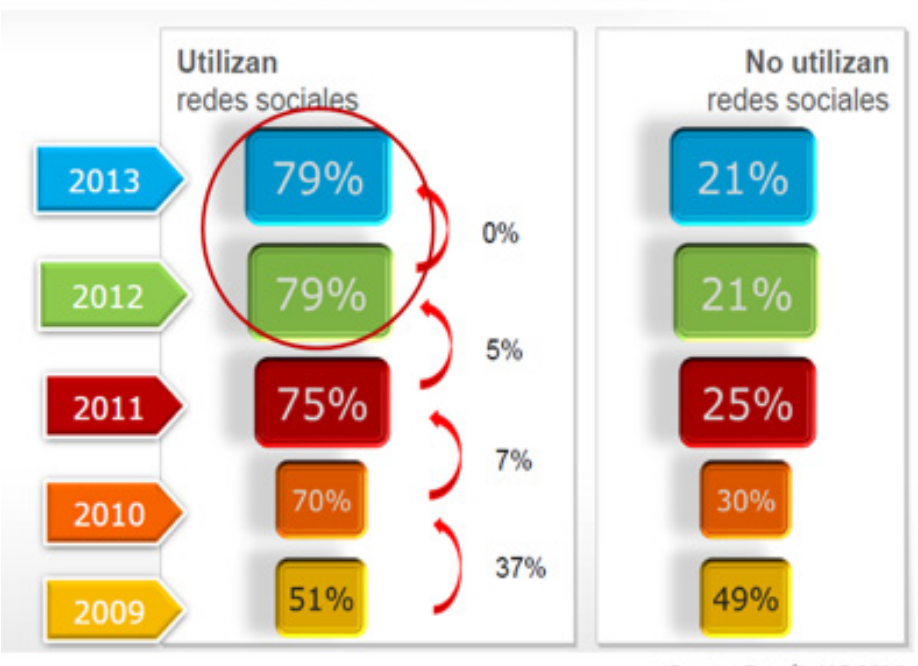

Fuente: Estudio IAB 2014

Figura 1: Número de usuarios con presencia en RRSS, datos 2012-2013, Fuente de estudios IAB.

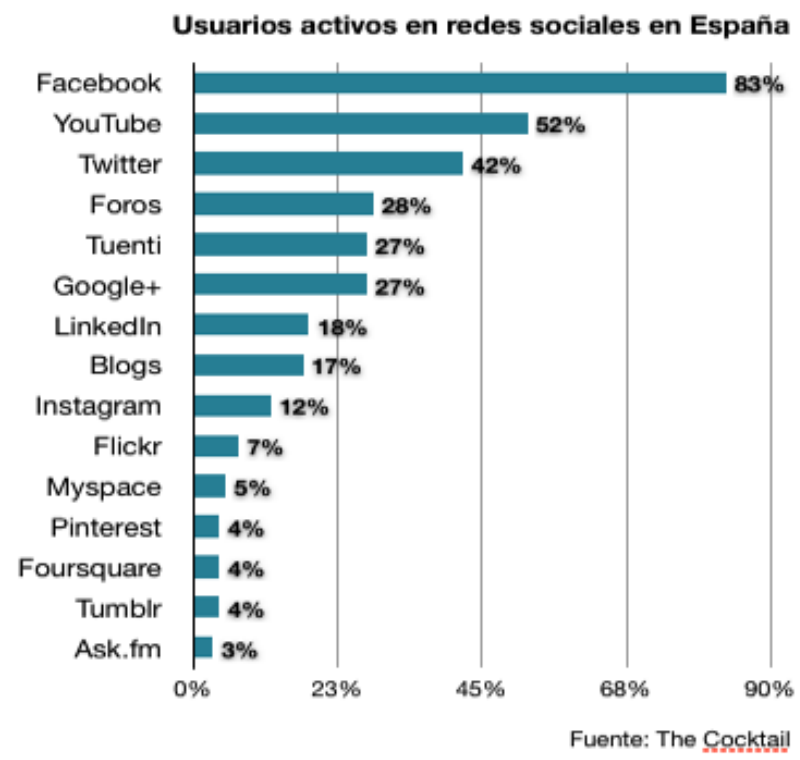

Figura 2: Datos de Comscore en España 2012 


\section{Internautas con redes sociales en España}

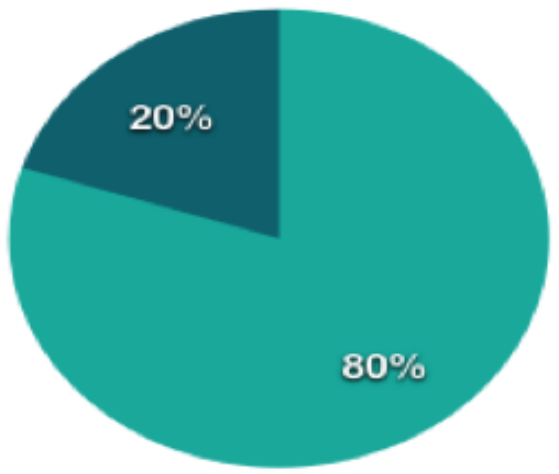

Con redes sociales

Sin redes

Figura 3: Datos de Comscore en España 2012

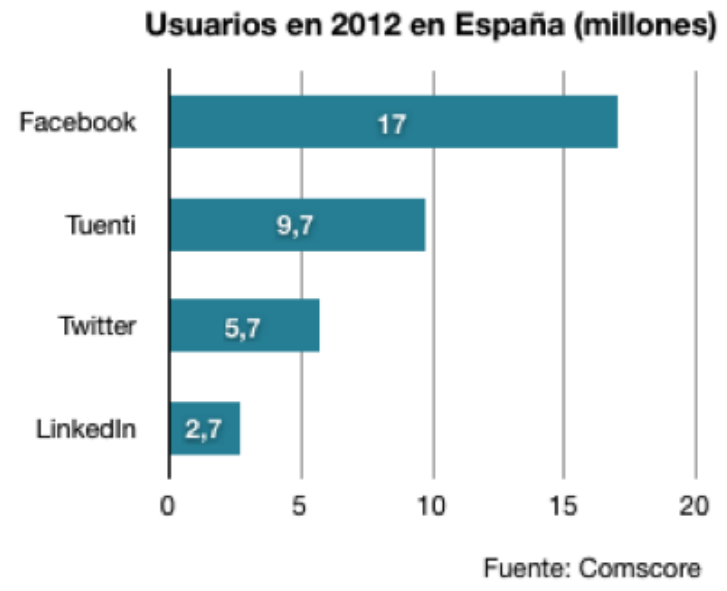

Figura 4: Datos de Comscore en España 2012

No todas las redes sociales que hay son válidas para llegar al posible público de un movimiento. Una vez que ha sido determinado el objetivo que se persigue, deberemos estudiar en qué redes nos es más viable estar y en cuáles de ellas alcanzaremos al segmento que estamos buscando y con el que crearemos vínculos. Las redes sociales se configuran como el tercer medio de contacto entre los más

DOI: ril4.v13i1.744 | ISSN: 1697-8293 | Año 2015 Volumen 13 N¹ | ICONO14 
jóvenes desde 2012, únicamente por detrás del teléfono móvil y la comunicación en persona (Fernández Torres, M. J.; Paniagua Rojano, F.J., 2012). La interacción social constituye una de las principales actividades de la población española en Internet, como hemos señalado.

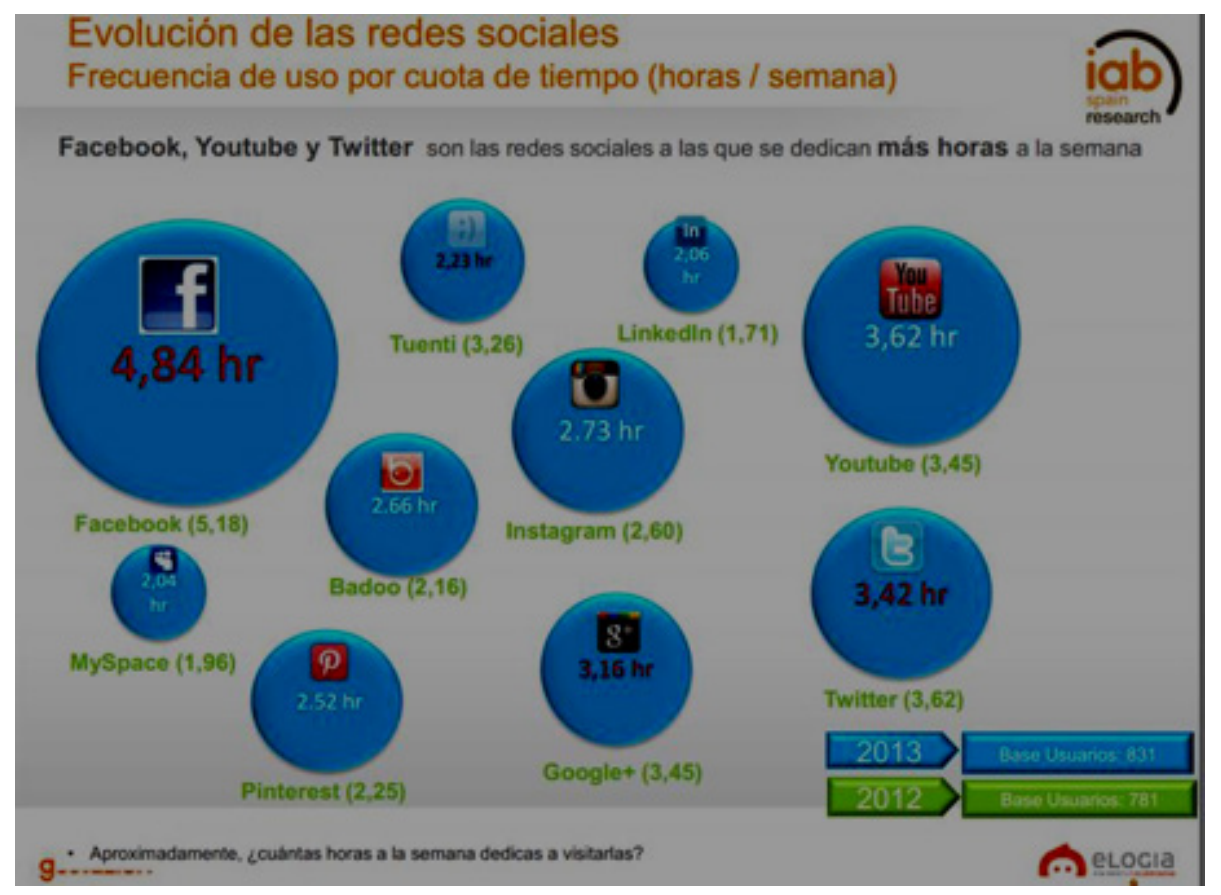

Figura 5: Fuente; Interactive Advertising Bureau, evolución de las redes sociales 2013-2012

Facebook está en continua expansión. Es la más extendida a escala mundial. Permite la incorporación de widgets que pueden ser utilizados para redireccionar a la página oficial del movimiento. La edad media de los usuarios de Facebook es más flexible que la de Tuenti, franja desde los 20 años en adelante, cada vez se están incorporando más personas provenientes de grupos como mayores de 35 años, y amas de casa. Tuenti es una red social enfocada principalmente a un público objetivo muy concreto. Demográficamente está extendida principalmente en España y son jóvenes, principalmente. Ahora bien, ya no es aquella red social que utilizaban muchos jóvenes españoles hace algunos años para comunicarse entre sí con la garantía de encontrarse en un lugar privilegiado y privado -al principio había 
que ser invitado por alguien para registrarse y sus contenidos no se indexaban en buscadores-. Esta plataforma sigue permitiendo la creación de eventos y de grupos de discusión. Esto último se puede utilizar como estrategia para hacer preguntas a los líderes del movimiento, o que los usuarios expongan un problema y el representante diga como lo solucionaría.

MySpace, a diferencia de Facebook o Linkedin, añade contactos no conocidos en el mundo off line, lo cual proporciona una ventaja de la marca personal del movimiento como primera toma de contacto. Linkedin es una red de contactos profesionales. En este caso, los profesionales que se encuentren en la red preguntan al movimiento 0 a sus representantes cómo solucionaría un problema o qué puede aportar esa organización a su empresa (Harfoush, 2010).

Twitter es, sin embargo, una herramienta de microblogging cada vez más potente. Se basa en la premisa de transmitir ideas en tan sólo 140 caracteres y actualizar los estados frecuentemente. Puede ser muy útil para transmitir las ideas del movimiento de protesta, incluso su programa punto por punto de forma resumida y accesible para la comunidad, y que de este modo cada entrada o "tweet" generado pueda ser comentado por el resto de usuarios (Orihuela, J., 2011).

No importa cuántas personas sigan un perfil de Twitter, ni cuántos actores proactivos existan se tenga en Facebook, sino la actividad de los contactos y la implicación que tengan con el movimiento a la hora de dejar comentarios en otros muros y actualizar sus propios perfiles. Es por eso, que se premia e incentiva conductas activas dentro de la red social, y no el efecto pasivo que analiza la estructura desde fuera sin llegar a implicarse (Harfoush, 2010).

De este modo, si por un lado los conjuntos de medios sociales como Twitter y Facebook favorecen la conformación global, transnacional y transversal de las protestas, por el otro permiten el control institucional de los datos grabados por los manifestantes. Esta contradicción, que está en el núcleo de las movilizaciones contemporáneas, no sólo los caracteriza, sino que se erige como un desafío a todas las demás formas de red de acción colectiva.

DOI: ri14.v13i1.744 | ISSN: 1697-8293 | Año 2015 Volumen 13 Nº 1 | ICONO14 


\section{Frecuencia de uso de WhatsApp en España}

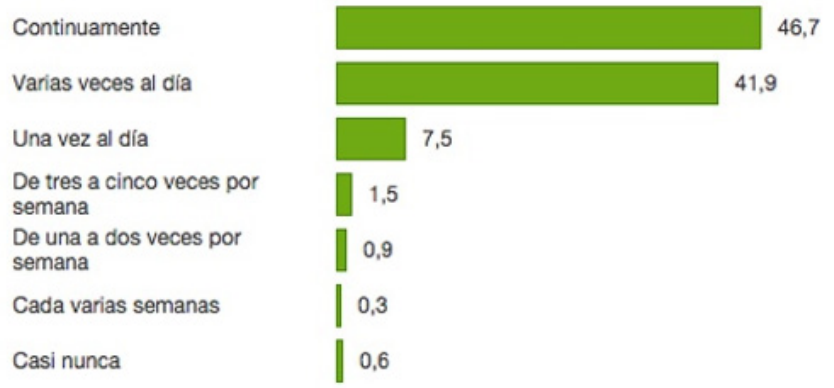

Fuente: Barómetro del CIS. Septiembre 2014.

Figura 6: Barómetro del CIS. Septiembre 2014

El problema actual es que WhatsApp se define como un servicio de mensajería instantánea, tal y como afirman en su web. Pero lo cierto es que podría convertirse, si no lo es ya, en algo más. La aplicación tiene todo para ser una red social ya que, aunque sea algo distinta a las redes sociales que conocemos, comparte muchas características con cualquiera de ellas (tener un perfil, conversar, compartir archivos y hacer grupos cómo en cualquier red social, no hay timeline, o hay mucha más conversación y menos exposición de datos). La pregunta sería: ¿Podemos considerar a WhatsApp una red social o sólo un servicio de mensajería instantánea?

\section{Conclusiones: el marco viral de los movimien- tos sociales}

1. El modelo de acción colectiva, ya no se construye a través del reconocimiento, sino a través de un nuevo modelo cultural, alterado por las TIC, que sigue siendo autorreflexivo. Es necesaria una forma organizativa tendente, por tanto, a maximizar recursos de solidaridad.

2. Los aspectos psicosociales fundamentales, como la construcción social de la realidad, la identidad colectiva, los valores y la toma de conciencia social 
requieren un nuevo giro. Sin embargo, hay que respetar los códigos. Cada red social tiene un público objetivo muy determinado, $\mathrm{y}$, por tanto, a la hora de elaborar una estrategia de marketing político se debe conocer el código de conducta de esa red (Harfoush, 2010).

3. Si no hay una interacción ni una comunicación bidireccional por parte del demandante y oferente, no hay comprensión del mensaje. Esto significa que se asume los procesos de comunicación como dinámicos, en dos vías y con posibilidades de feedback o lo que Castell ha llamado "la autocomunicación de masas como producto del uso de las nuevas TICs en la comunicación social" (Castell M. 2009). Habrá que publicar información propia y ajena. No sólo debe actualizarse el canal con contenidos propios hechos por el movimiento o promovidos por el mismo, sino que debe publicar las actividades interesantes hechas por los miembros de la red. Hay que añadir narraciones (story telling) desde distintos puntos de vista, pero con un único objetivo.

4. Las redes sociales son un instrumento para la convocatoria de la movilización social. Sin embargo, es necesario realizar búsquedas fuera de las redes sociales e interactuar en foros. Tan importante es lo que se diga de una marca tanto dentro de las redes sociales como en el entorno web. Para ello, se debe contar con creadores de corrientes de opinión o usuarios afines al movimiento en plataformas diversas.

5. El proceso de comunicación debe ser concebido desde una lógica política democrática, en la que hay competencia y concurso por la protesta, en la que la autoridad es elegida en elecciones libres, en la que hay derechos y libertades. La libre competencia es la tónica general permite la maximización de los intereses selectivos.

6. Las redes sociales consiguen una fácil medición del éxito que esté teniendo la acción colectiva, de si ha sido absorbida por el público objetivo $\mathrm{y}$, en último caso, de modificar la campaña en caso de ir mal encaminada. Es en esta última parte, donde las redes sociales pueden ayudar más al movimiento. 
7. Estamos ante el reconocimiento de marca (brand awareness) de un movimiento mediante procesos de autorreplicación viral, análogos a la expansión de un virus informático. El mecanismo es el boca a boca de los ciberactivistas mediante medios electrónicos, que usa el efecto de "red social" creado por Internet, y los modernos servicios de telefonía móvil para llegar a una gran cantidad de personas rápidamente. La trasparencia, el respeto y compartir información deben ser las premisas que rijan la presencia del movimiento social, y eviten un deterioro de su imagen en la Web. Esta dimensión se plantea en términos de "contextos" en plural, para dar una idea de complejidad de la dinámica que en ellos se produce y sobrepasar el esquema estático del "emisor-receptor" del proceso de comunicación tradicional.

\section{Referencias}

Barquero Cabrero, J. D. (2005), Comunicación estratégica: relaciones públicas, publicidad y marketing, Madrid, McGrawHill.

Benett, W. (2003), “Communicating Global Activism: Strengths and Vulnerabilities of Networked Politics", in Information, Communication \& Society, vol. 6, no. 2, 143-68.

Borge Bravo, R. (2005), “La participación electrónica: estado de la cuestión". Revista de Internet, Derecho y Política, Barcelona, UOC.

Cammaerts, B., Van Audnhove, L. V., (2003), “ICT-Usage among Transnational Social Movements in the Networked Society: to organise, to mediate \& to influence, rapporto di ricerca di", The European Media and Technology in Everyday Life Network (EMTEL).

Calvo Fernández, S.; Reinares Lara, P. (2001), Comunicación en Internet.

Estrategias de Marketing y Comunicación Interactivas, Madrid: Paraninfo.

Canel, MJ. (1999), Comunicación Política. Técnicas y estrategias para la sociedad de la información. Madrid, España: Editorial Tecnos S.A.

Castells, M. (1997), El poder de la identidad. Madrid: Alianza. (Vol. 2 de La era de la información)

Castells, M. (2001), La Galaxia Internet, Barcelona: Plaza y Janés; (2003): La Galaxia Internet. Mondadori. Barcelona.

Castells, M. (2009). Comunicación y poder. Madrid, España: Alianza Editorial. 
Colombo Villarrasa, C. (2007), E-Participación. Las TIC al servicio de la innovación democrática, Barcelona: UOC.

Comisión Nacional de los Mercados y la Competencia (2014). Informe sobre servicios over the top en España.

Fernández Torres, M. J.; Paniagua Rojano, F.J., (2014), “El poder de las redes sociales en La política y en los movimientos sociales", Congreso Alice, Madrid 2012.

Funes, M.J, (2011), “La política no convencional ja escena!", Anuari conflicte social.

Fundación Orange (2014), Informe eEspaña, 2014. Harfoush; R., (2010), Yes we did, Tu Gestion 2000.

Hirschman, A. (1986), Interés privado y acción pública, Fondo de Cultura Económica, México.

Lambin, J.J. (2003), Marketing estratégico. ESIC.

Lasen, A. \& Martinez, I. (2008), “Movimientos, "mobidas” y móviles. Un análisis de las masas mediatizadas" en SádabA, I; Gordo, Á. (Coords.) (2008): Cultura digital y movimientos sociales. Madrid. Catarata.

León, 0.; Burch, S.; Tamayo, E. (2001), “Movimientos sociales en la Red”. ALAI. Dirección: http://alainet.org/publica/msred/

Marí Sáez, V.M. (2006), “El deseo de enredarse y el peligro de liarse. Un autodiagnóstico sobre los procesos de apropiación de internet por parte de los movimientos sociales y la ciudadanía activa". Revista Textos de la CiberSociedad [en línea]. 2006, no 9 [consulta 23 octubre 2014]. Formato html. http://www.cibersociedad.net/textos/articulo.php?art=80

Montañés del Río, M.A.; Serrano Dominguez, C; Medina Garrido, J.A. Morales, D. (de), Marketing Técnicas de Marketing viral (2014): ESIC.

Morales, D. (de) (2007), Sociedad Mediatizada. Gedisa. Barcelona.

Sibaja Quesada, G. (2013), "Modelo para el estudio de la comunicación política", en Crespo I.; Del Rey J., Comunicación politica-Campañas electorales en América latina, Alce, Editorial Biblos/Politeia.

Sey, A.; Castells, M. (2006), “De la política en los medio a la política en red: Internet y el proceso político". En M. Castells (Ed.), La Sociedad Red: un visión global, Alianza, Madrid. 
Tarrow, S. (1997), El poder en movimiento. Los movimientos sociales, la acción colectiva y la política. Alianza. Madrid.

Orihuela, J. (2011), Mundo Twiter, Barcelona, Alienta

Ugarte (de), D. (2007): “El poder de las redes. Manual ilustrado para personas, colectivos y empresas abocados al ciberactivismo" Dirección: http://www. deugarte.com/manual-ilustrado-para-ciberactivistas.

Wolton, el al, (1998), El nuevo espacio público. Gedisa Editorial, Col. El mamífero parlante, Serie mayor, Barcelona.

IV Estudio de Redes sociales online de Interactive Advertising Bureau (IAB Research Spain) de enero de 2013. 